\title{
Permeation Barrier Coatings for the Helical Heat Exchanger
}

by

P. S. Korinko

Westinghouse Savannah River Company

Savannah River Site

Aiken, South Carolina 29808

N. Thakur

A document prepared for ALTERNATE COATINGS WORKSHOP at Richland, WA, USA from 5/18/99 - 5/19/99.

DOE Contract No. DE-AC09-96SR18500

This paper was prepared in connection with work done under the above contract number with the U.S.

Department of Energy. By acceptance of this paper, the publisher and/or recipient acknowledges the U. S.

Government's right to retain a nonexclusive, royalty-free license in and to any copyright covering this paper, along with the right to reproduce and to authorize others to reproduce all or part of the copyrighted paper. 


\section{DISCLAIMER}

This report was prepared as an account of work sponsored by an agency of the United States Government. Neither the United States Government nor any agency thereof, nor any of their employees, makes any warranty, express or implied, or assumes any legal liability or responsibility for the accuracy, completeness, or usefulness of any information, apparatus, product, or process disclosed, or represents that its use would not infringe privately owned rights. Reference herein to any specific commercial product, process, or service by trade name, trademark, manufacturer, or otherwise does not necessarily constitute or imply its endorsement, recommendation, or favoring by the United States Government or any agency thereof. The views and opinions of authors expressed herein do not necessarily state or reflect those of the United States Government or any agency thereof.

This report has been reproduced directly from the best available copy.

Available to DOE and DOE contractors from the Office of Scientific and Technical Information, P. O. Box 62, Oak Ridge, TN 37831; prices available from (423) 576-8401.

Available to the public from the National Technical Information Service, U. S. Department of Commerce, 5285. Port Royal Road, Springfield, VA 22161. 


\section{DISCLAIMER}

Portions of this document may be illegible in electronic image products. Images are produced from the best available original document. 
WSRC-TR-98-00429

SMTD

STRATEGIC MATERIALS TECHNOLOGY DEPARTMENT

Keywords: Barrier Coatings

Tritium

Stainless Steel

Retention: Permanent

\title{
Permeation Barrier Coatings For the Helical Heat Exchanger
}

\author{
By \\ P. S. Korinko \\ and \\ N. Thakur
}

Issued: November 1998

\section{UNCLASSIFIED}
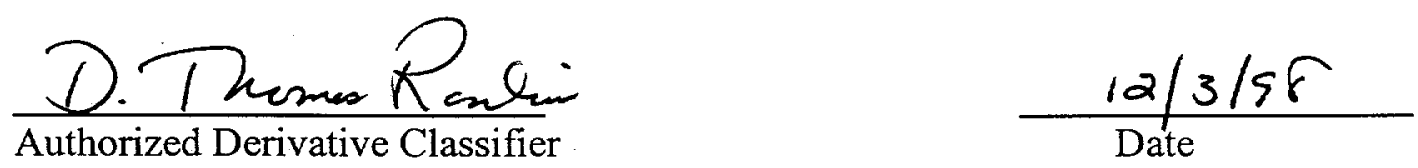

SRTC: SAVANNAH RIVER TECHNOLOGY CENTER, AIKEN, SC 29808

Westinghouse Savannah River Company

Prepared for the U.S. Department of Energy under Contract DE-AC09-96SR18500 


\section{WSRC-TR-98-00429}

DOCUMENT: $\quad$ WSRC-TR-98-00429

TITLE:

PERMEATION BARRIER COATINGS FOR THE HELICAL HEAT EXCHANGER

APPROVALS:

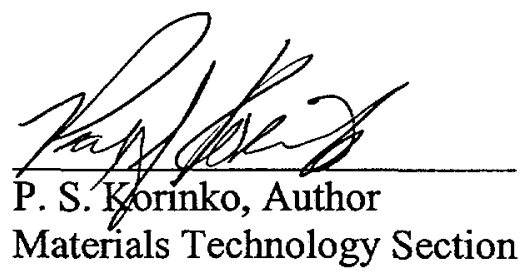

$\frac{12-3-98}{\text { Date }}$

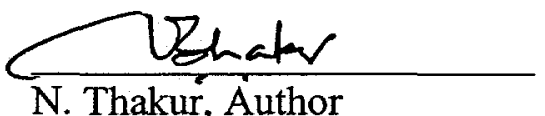

Design Execution

$\frac{12 / 3 / 98}{\text { Date }}$

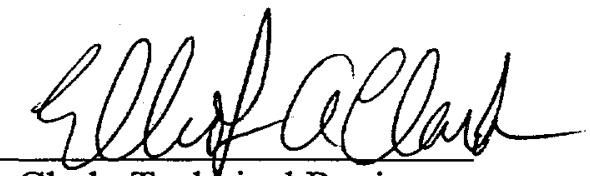

E. Clark, Techhical Reviewer Materials Technology Section
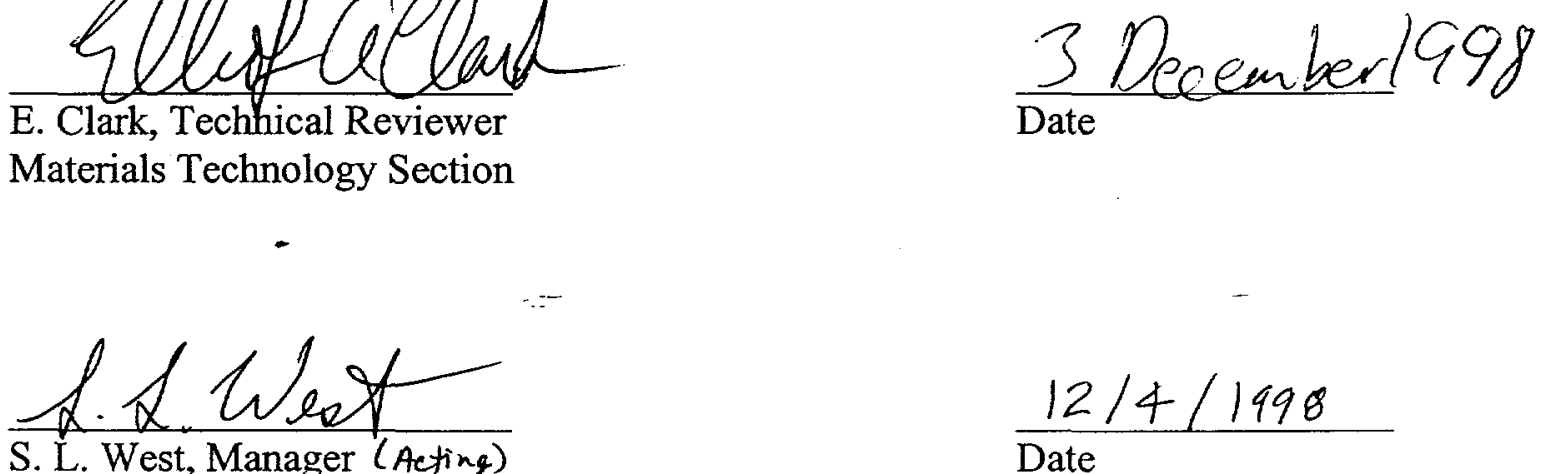

Materials Compatibility and Joining Technology Group

$\frac{12 / 4 / 1998}{\text { Date }}$

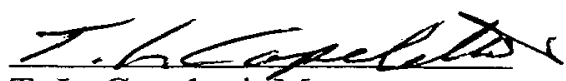

T. L. Capeletti, Manger Materials Technology Section

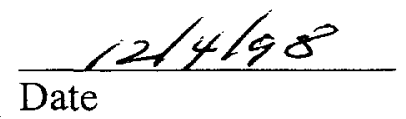




\section{Permeation Barrier Coatings For the Helical Heat Exchanger}

\section{Summary}

A permeation barrier coating was specified for the Helical Heat Exchanger $\mathrm{HHE}$ to minimize contamination through emissions and/or permeation into the nitrogen system for ALARA reasons. Due to the geometry of the HHE, a special coating practice was needed since the conventional method of high temperature pack aluminization was intractable. A survey of many coating companies was undertaken; their coating capabilities and technologies were assessed and compared to WSRC needs. The processes and limitations to coating the HHE are described. Slurry coating appears to be the most technically sound approach for coating the HHE.

\section{Background:}

Hydrogen isotope permeation is a significant problem at elevated temperatures. Release of these isotopes can be reduced using protective coatings. Several types of coatings, comprised of gold, titanium compounds such as titanium nitride and titanium carbide, some refractory metals, and iron aluminide have been successfully tested and shown to limit the permeation of the isotopes (1). Selection of a coating type for a given application involves evaluation of positive and negative attributes including cost, size limitations, flexibility, etc. The Savannah River Site has used aluminide coatings in the past as tritium permeation barriers. This coating has been demonstrated to decrease the permeation rate by factors of 10 to over 1000 (2).

Hydrogen permeation can be described as a process of adsorption, dissociation, diffusion, recombination, and desorption of a hydrogen molecule. Any material or process that inhibits any of the steps will reduce the permeation rate. It is an overall reduction in permeation rate that the aluminide coating accomplishes. A likely, though not entirely agreed upon mechanism, is that the aluminide layer, being rich in aluminum, readily oxidizes to form aluminum oxide which has a much lower diffusivity thän the alloy. This oxide layer, though very thin, consequently decreases the permeation rate. A monolithic ceramic coating could be conceived of as a permeation barrier, but due to thermal expansion mismatch would be prone to spallation; its lack of ductility would make it prone to cracking. Ideally, the coating should form the oxide layer "in-situ" and be able to "heal" itself. An aluminide coating offers these attributes. The ability of an aluminide coating to form aluminum oxide and reform the oxide upon spallation is one reason it is so widely used in high temperature applications such as gas turbine engines.

The coating is being applied to the HHE to minimize the level of contamination through emission and/or permeation from the coil into the nitrogen system for ALARA reasons.

\section{Aluminizing methods}

There exist a number of methods to apply aluminide coatings as enumerated below. These 
methods, the benefits, and limitations of each will be briefly described.

1. Pack aluminization

A. Low temperature

B. High temperature

2. Gas Phase

A. "Above the pack"

B. Chemical Vapor Deposition (CVD)

3. Slurry Coatings

A. Gas phase

B. Liquid phase

4. Other
A. Electrophoretic
B. Tape

Pack aluminization is a coating technique that applies aluminum to the surface by placing the component to be coated in a large retort. The retort is typically packed with an aluminum alloy, a halide activator (such as ammonium chloride), and an inert filler (aluminum oxide). The loaded retort is subsequently placed in a furnace and argon or another inert gas purges the system to prevent oxidation. As the furnace and retort are heated the aluminum melts, combines with the halide and forms an aluminum rich gas. Aluminum halide (typically chloride) diffuses to the component surface, the aluminum is reduced and reacts and forms an iron aluminide (on stainless steel parts). The halide is then freed and it either reacts with additional aluminum and the process is continued repeated or the halide it is swept away by the purge gas. The aluminide thickness increases as a function of the aluminum activity, time, and temperature. In general, the process can occur at low temperatures $\left(1400-1800^{\circ} \mathrm{F}\right)$ for $4-20$ hours or high temperatures (1800$2000^{\circ} \mathrm{F}$ ) for 2-8 hours. At low temperatures, the diffusion conditions are such that an inward growing, high aluminum content iron aluminide coating is deposited. This coating has a distinct microstructure and will tend to be higher in $\mathrm{Al}$ than the high temperature diffused coating which tends to be an outward grown aluminide. In the outward diffusing coating, the aluminum reacts at the surface and some is transported inward while iron and other base metal elements diffuse outward. The outward coatings will be result in very little added material to the surface (30$60 \%$ ) while an inward type coating will tend to be $60-90 \%$ additive. In reality, there are vestiges of both inward and outward type diffusion in most coatings. A post coat diffusion cycle may be used to reduce the surface aluminum content and thereby reduce the aluminum concentration profile, which improves the coating ductility. For the pack and other vapor phase processes that use chlorides, there is no control on the residual chloride concentration.

There are two types of gas phase processes; those that have the aluminum vapor generated in-situ (also called "above-the-pack" or "out-of-pack") and those generated ex-situ such as chemical vapor deposition (CVD). In the above-the-pack process, pack materials as described above ( $\mathrm{Al}$ source material, activator, and inert filler, if required) are placed into a special multi-chamber retort that has gas flow tubes to interconnect the chambers and to provide aluminum gas to the part. The retort is heated and an aluminum rich gas forms and the balance of the process is essentially the same as for the pack method. The CVD process can be conducted either at low temperatures using organometallic precursors (OM-CVD) or at high temperatures using 
aluminum or aluminum alloys and halide gas activators and a hydrogen carrier gas. The $\mathrm{Al}$ source for CVD is outside of the coating chamber and is piped in to the retort. At high temperatures, the $\mathrm{Al}$ gas reacts and forms the aluminide in much the same manner as the gas phase or pack. For the low temperature OM-CVD process, the reaction takes place below the melting point of $\mathrm{Al}$ and pure elemental $\mathrm{Al}$ is deposited. The coated part is then heat treated to form the aluminide. The diffusion heat treating time and temperature dictate the coating thickness and chemistry.

Slurry coatings are used to apply aluminum source material by spraying or painting aluminum or an aluminum-alloy on the surface. The coated part ("green part") is cured at a temperature less than $650^{\circ} \mathrm{C}$ and diffusion heat treated. This method permits coating of large complex shapes that have few blind areas, as it is somewhat a line-of-sight process. Within the slurry coating method either liquid phase or vapor phase transport can occur. The transport mechanism depends on the composition of the slurry and the aluminum source alloy. If a vapor phase method is used, then the slurry contains activators, an aluminum source, and possibly inert fillers much like the pack processes. The coating mechanism is virtually identical to those described above. Whereas, if the liquid phase transport is used, then the painted on slurry contains either aluminum or an aluminum- alloy and possibly inert fillers or binders to provide green strength (strength before the part is diffusion heat treated). The part is green coated, the coating cured, and then heat treated by heating above the melting point of aluminum where the iron and aluminum interdiffuse to form the desired aluminide phase. The resulting coating depends on the aluminum activity of the applied slurry and the diffusion conditions. Under the preferred conditions, the final coating thickness should be independent of the amount of slurry applied once a threshold amount has been exceeded. For this condition, the coating is diffusion limited opposed to green coat limited. In other words, additional green coating materials do not increase the diffused coating thickness. From a processing viewpoint, the diffusion heat treat-limited condition promotes a more robust coating process since the amount of coating on a complex part can vary widely without causing a wide variation in the coated product.

There are also other methods to apply aluminum source material to the parts. The tape method is similar to the slurry method in that aluminum source material is applied at room temperature. The tape contains organic binders, activators, and inert fillers, to provide strength and aluminum source material. The tape is applied to the surface of the part and the part is diffusion heat treated using a controlled thermal cycle to burn out the binder and to react the aluminum source material with the part. The final coating composition and microstructure are determined by the aluminum activity in the tape and diffusion heat treating conditions. Another method is to apply the aluminum source material using a binder in a solution and electrophoresis. The aluminum alloy is then heat treated to form the aluminide. The final method to mention is dipping the part into molten aluminum, permitting the surface reaction and diffusion heat treating the part to achieve the final coating.

In all of the cases, the coating microstructure will consist of two or more distinct layers. There is an aluminum rich aluminide surface layer and an interdiffusion layer. The external surface aluminide can have either an equiaxed or columnar grain structure depending on the growth conditions. 


\section{Limitations of each process for HHE}

During preliminary design of the Helical Heat Exchanger (HHE) coil, the normal site vendor for aluminide permeation barrier coatings (Alon) was contacted. They were asked to provide a quotation for coating a tube in tube (HHE). They determined that they would be unable to provide a suitable coating for several reasons. First, since an internal coating was required, they thought it unlikely that they would get void free fill and the resulting air pockets could then cause problems with burn through during the aluminizing treatment. Second, the thickness uniformity for a 0.035 wall was such that they considered it possible that the coating thickness may be as high as 0.020 inches to ensure a minimum thickness of 0.003 inch. This aluminide thickness could cause embrittlement at the thickest coating locations. (The reason for the variation in coating thickness occurs since it is difficult to get uniform heating in a large retort and some sections of the HHE coil would be at the coating temperature for longer times which would promote a thicker coating.) A reason WSRC chose not to pursue this coating source is that with the thickest coating, the HHE may not have met the design strength and ductility requirements. Other vendors that provide pack aluminides, Chromalloy and Howmet, were contacted. Chromalloy suggested using a high temperature pack process at a temperature of $1975^{\circ} \mathrm{F}$, however, this temperature is at the melting point of copper and is unacceptable since the inside of the HHE is packed with copper foam to improve heat transfer. Howmet offers both low and high temperature pack aluminides. They did not have a retort of appropriate geometry so a new one would have to be fabricated at significant expense. In addition, they do not have experience coating- Type 316L stainless steel. The cost and lead times for these items precluded their participation in a development activity.

The use of a gas phase process offers the best opportunity to coat complex shaped components such as the HHE. The primary limitation is the need for a reactor of an appropriate size and geometry to accommodate the part. A Canadian firm Liburdi was identified who can apply aluminides by the low temperature CVD method. They also have experience coating stainless steel. Unfortunately, their CVD chamber is smaller than the HHE coil. In addition, they were unwilling to apply for the required state department export license as required for the nonproliferation act. Walbar Metals and Turbine Components Corporation were contacted as sources for the high temperature CVD and a high temperature gas phase aluminide coatings, respectively. Neither company has appropriately sized retorts or experience coating Type 316L stainless steel.

Alternate methods that are not reliant on specific geometries were considered. This left slurry methods, tape, and others. Tape applications are widely used as a touch procedure for small areas on turbine blades in General Electric's turbine engines. The touch up is used to rework blades that need localized repair. The use of the tape on large scale components requires full coverage of the tape and a furnace system capable of removing large amounts of binders. Trials for this project were conducted on small scale components with limited success. Several additional trials, and possibly tailoring the composition of the powders may be necessary before this coating methodology could be implemented. No commercially available sites for electrophoretic deposition were contacted but specialized anodes and a large tank would have to constructed to accommodate the HHE geometry. The process would need to be developed to ensure that a uniform coating would be achieved. 
Based on technology and equipment limitations listed above, costs, familiarity with the base metal, and other factors, slurry coatings appear to be application method of choice. Two coating vendors were contacted. Liburdi was interested from the technology standpoint since they have been developing slurry type coatings, however, the political and legal requirements prevented them pursuing the coating on the HHE. The American firm Sermatech was identified as a company who is well known in the aerospace industry for applying aluminides by slurry methods. They expressed an interest in the application and had experience with coating stainless steel alloys. They also have experience with the particular temperature requirements that were applicable to the HHE assembly. Proof of concept work was necessary to validate their capabilities.

\section{Evaluation of Sermatech Slurry coatings}

Trials using the Sermatech slurry coatings were initiated to determine the feasibility of coating the HHE using three commercially available slurry compositions and WSRC diffusion temperature limitations. It was decided to evaluate to two liquid phase diffusion slurries (SermeTel 962 and SermeTel 963) and one vapor phase diffusion slurry (SermAlcote 1619). The detailed report of the results is attached as appendix A. In summary, one liquid phase diffusion coating system SermeTel 963 is able to apply a coating that meets or slightly exceeds the preliminary technical requirements for the HHE; the thickness and aluminum content are slightly greater than that specified in the statement of work, appendix B. This slight increase over the specified amount for both thickness and aluminum content should be acceptable since others in the field of permeation barriers recommend much higher Al contents (1). The microstructure exhibits the desired two-layer structure with the outer layer exhibiting an equiaxed grain morphology. The coating had a more desirable surface roughness that was seemingly very low; a smooth surface was evident.

The vapor phase coating (SermAlcote 1619) met the thickness and aluminum content requirements of the SOW. It had two attributes that were not as desirable as the liquid phase process, both of which can likely be attributed to the method by which the aluminide is deposited. The first is the columnar grains in the coating. It is possible that this orientation could promote fatigue initiation sites at the grain boundaries perpendicular to the surface. The other less desirable attribute is in the slightly rougher surface as shown in the coating micrograph; this could be strictly a cosmetic issue.

A simple micro-hardness test (Diamond pyramid indenter 100gf) was used to evaluate the coating ductility. In this test, the indenter is pressed into the sample and the impression is examined. The presence of cracks indicates that the coating (sample) is brittle while the absence of cracks imply some ductility. The post-test examination of the SermeTel 963 and SermAlcote 1619 did not reveal cracks emanating from the corners of the hardness impression. The report does show cracks in the outer layer of the coating. The cracks arrest at the outside surface of the inter diffusion zone. The Sermatech report is attached as Appendix C.

A metallographic examination of the coated tube sections was conducted at SRS. A copper tube coated with SermeTel 963 was sectioned and the copper foam and coating microstructure were 
examined. The copper foam was oxidized, a condition consistent with the environment on the inside of the tube which had been seal welded and subsequently drilled out to release any pressure build-up during the diffusion heat treat cycle. The hole was masked with a compound to minimize contamination of the furnace atmosphere with copper vapors, however, the internal was oxygen enriched. The fit of the copper foam could not be determined since the original condition was unknown. For the actual HHE, the tube interior will be evacuated and sealed so there will be no oxidation of the copper foam; sealing the tube segments was done to prevent contamination of the copper foam with aluminum while drilling them was an after thought to prevent excess pressure build up which was a vendor concern.

The coating was of uniform thickness and nominally 0.0044 inches thick. The surface exhibited some small depressions. Fine crack like indications were observed in the outer layer of the coating. The cracks arrested at the outer edge of the diffusion layer. Penetrant oil testing (PT) was conducted to determine if the cracks are visible in the as-received condition. There were no cracks observed with the PT. The PT report is attached as Appendix D

\section{Discussion}

Since the permeation barrier coatings that have been in service at WSRC have not been adequately characterized except based on thickness and process, it is difficult to know the aluminum content in the coating. Based on the process temperature, it is highly likely that an outward diffusing, low aluminum content coating has performed successfully in reducing tritium permeation to acceptable levels. This anecdotal information encourages selecting a coating process that meets the thickness requirements on other WSRC components. The microstructures of the Sermatech coatings are similar to the Alon coating (3).

There is a difference in the surface roughness of the two coating methods used by Sermatech. The surface was considerably rougher for the vapor phase than for the liquid phase. The relative merit for each should be evaluated. The final determination of which method should be used needs to be based on these additional factors since either method will produce coatings that meet the thickness and chemistry requirements.

The grain orientation of SermAT cote 1619, vapor deposited aluminide, is undesirable and may promote fatigue cracking especially since the application is cyclic with a design life of 400,000 cycles. In order to minimize the effect of the coating on fatigue life; a coating that has a more favorable equiaxed grain structure should be specified.

\section{Recommendations}

Based on past WSRC experience with what is likely a high temperature, low activity pack aluminide coating as a permeation barrier, the use of the Sermatech aluminide coatings should be successful in reducing tritium permeation. Although both the vapor phase and liquid phase methods meet the technical requirements, the liquid phase SermeTel 963 should be used since it exhibits a favorable equiaxed grain structure. 


\section{References}

1. E. R. Gilbert, R. P. Allen, D. L. Baldwin, R. D. Bell, J. L. Brimhall, R. G. Clemmer, S. C. Marschman, M. A. McKinnon, R. E. Page, H. G. Powers, S. G. Chalk, "Tritium Permeation and Related Studies on Barrier Treated 316 Stainless Steel," Fusion Technology, Vol. 21, March 1992, pp. 739-744.

2. G. W. Hollenburg, E.P Simonen, G. Kalinin, and A. Terlain, “Tritium/Hydrogen Barrier Development", Fusion Engineering and Design, 28 (1995) pp. 190-208.

3. 200-H area Metallurgical Report, File code H-232-Miscellaneous, Dec. 1980. 
WSRC-TR-98-00429

Appendix A

SERMATECH METALLURGICAL REPORT

$-$




\section{SLURRY ALUMINIZING OF 316L STAINLESS STEEL}

\section{Background:}

Westinghouse/Savannah River needs to protect the outer surface of a coiled tube heat exchanger made of $316 \mathrm{~L}$ stainless steel against corrosion and oxidation. The coil is about 2 feet in diameter and about 30 inches tall and is made of $1.1 / 2$ " diameter stainless steel tubing filled with copper foam. The purpose of this project was to evaluate slurry aluminides on $316 \mathrm{~L}$ stainless steel tubes and panels supplied by Westinghouse/Savannah River. Samples were diffused below $1000^{\circ} \mathrm{C}(1835 \mathrm{~F})$ to prevent sintering of the copper metal foam inside the tubes. The parts were diffused in argon, rather than a vacuum so copper would not vaporize at these temperatures. The content of aluminum in coatings was determined by SEM/EDAX in accordance with the statement of work provided by Westinghouse/Savannah River under purchase order PCP 12Q4A2404.

\section{Test Procedure:}

Westinghouse supplied 6 sections of stainless steel tube, each approximately 4 inches long. Three of the sections were filled with copper foam, three were empty. All had been welded closed at both ends. Westinghouse/Savannah River also provided ten small coupons of $316 \mathrm{~L}$ stainless steel to accompany these parts. A small hole was drilled in each welded tube to relieve pressure during heating.

These specimens were divided into 3 groups. The first group was coated with SermeTel 962 . SermeTel 962 is an aluminum-filled chromate/phosphate ceramic slurry. Two coats of 962 were applied. Each coat was cured for $1 / 2$ hour at 650 degrees.

A second set of specimens was coated with one thick coat of SermaTel 963, another aluminum filled chromate/phosphate ceramic composite coating. SermeTel 963 is designed to produce thicker films than can be achieved in one pass with the SermeTel 962 material. Like SermeTel 962, SermeTel 963 was cured 1/2 hour at 343C (650F).

The remaining set of samples was coated with SermAlcote 1619. This organic slurry contains metal powders and chemical activators. The nature of the slurry is such that the exact amount applied is not critical for the final diffusion thickness. This coating was dried before further processing.

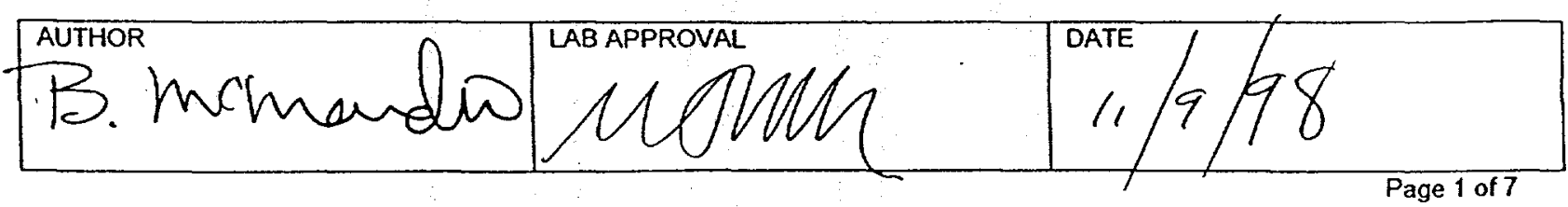


After all the samples had been coated, each was diffused for 4 hours at $980 \mathrm{C}$ (1800F) in argon at a dewpoint less than -40 degrees. At this temperature, the aluminum pigment in the SermeTel 962 and 963 coatings melts and begins to diffuse into the steel substrate. As the aluminum diffuses in, iron and nickel diffuse out. Iron and nickel are absorbed by the molten aluminum until the aluminum-iron-nickel mixture solidifies into an aluminum-rich intermetallic phase on the surface.

The mechanism by which the SermAlcote slurry forms an aluminide is very different. At the diffusion temperature, the chemical activators in the slurry react with the aluminum alloy powder to form gaseous aluminum halides. These halides migrate to the metal surface below where they are reduced, and aluminum is released into the metal. The aluminum diffuses into and reacts with metal to form intermetallic aluminides.

After diffusion, each group of parts and panels was lightly burnished with glass beads (300 mesh or finer) to remove undiffused residues. Sections from representative panels of each group were mounted and polished to reveal the structure of the aluminide. After the thickness of the aluminide coatings had been measured, samples were sent to Quali-Tech Inc. in Meriden Connecticut for determination of the aluminum content using SEM/EDAX.

\section{Results and Discussion:}

Optical Metallography revealed some similarities in the structure of each of the three coatings. Each coating appeared to consist primarily of two phases, the innermost layer being filled with fine, somewhat spherical precipitates. The outer layer of each coating was relatively free of precipitates. There appeared to be large equiaxed grains in the outer layer, these grains being particularly noticeable in coatings produced by diffusing SermeTel 963 and the SermAlcote 1619 slurries. The grains were especially noticeable in the 1619 slurry. These coating structures are shown in the photos which are attached.

The relative thickness of each of these phases varied from coating to coating. The thickness of each layer within the aluminide coatings is indicated in Table 1.

On the SEM, Quali-Tech identified a third very thin outer layer on the surface of each aluminide. 'The SEM/EDAX analysis also clearly identified significant differences in the aluminum content of the coating structures produced from the different aluminides.

The aluminide produced by SermeTel 962 had a very low aluminum content. The greatest aluminum content was found in the middle zone. That zone containted only $10 \%$ aluminum by weight.

The aluminum content in the middle of the coating formed by diffusing SermeTel 963 , was approximately $31 \%$ by weight. The outermost zone in that coating contained as much as $36 \%$ aluminum. 
The coating produced from the SermAlcote slurry contained about $24 \%$ aluminum by weight. The elemental compositions determined by Quali-Tech are reported in Table 1 of their report, which is attached. Also attached are SEM photographs of the coating structure showing the thin outermost zone covering what became known as the middle zone and inner zone of the coatings.

Conclusions:

1. SermeTel 962 and 963 and SermAlcote 1619 may be used to produce aluminide layers on $316 \mathrm{~L}$ stainless steel.

2. The SermAlcote 1619 slurry produces an aluminide containing about $24 \%$ aluminum by weight this would meet the target set by Westinghouse/Savannah River for the $316 \mathrm{~L}$ stainless steel heat exchanger they are designing. 


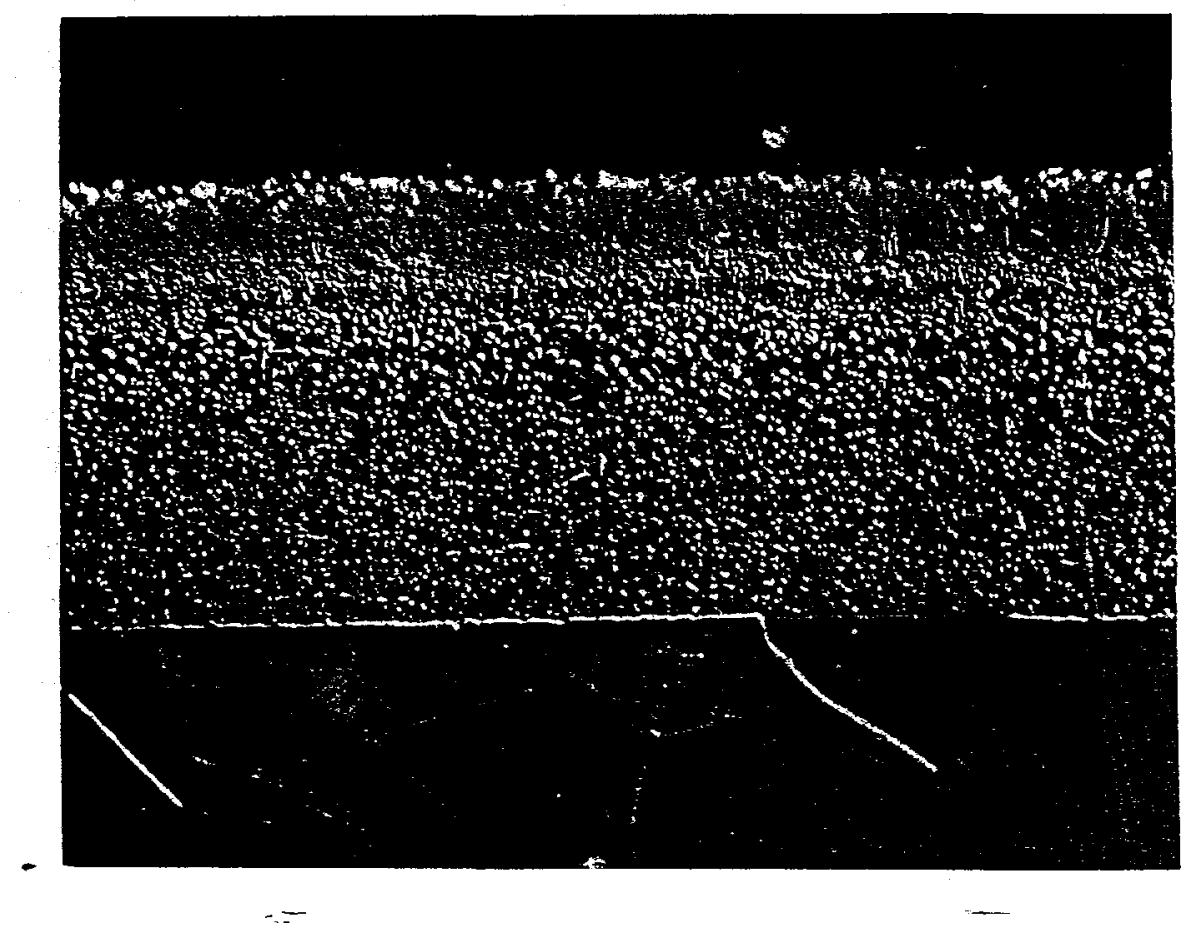

Photo 1: $\quad$ Aluminide produced by diffusing SermeTel 962 on a panel of $316 \mathrm{~L}$ stainless steel. This panel was diffused at $980 \mathrm{C}(1800 \mathrm{~F})$ for 4 hours in argon.

(mount A2088, unetched, differential interference contrast, 375x) 


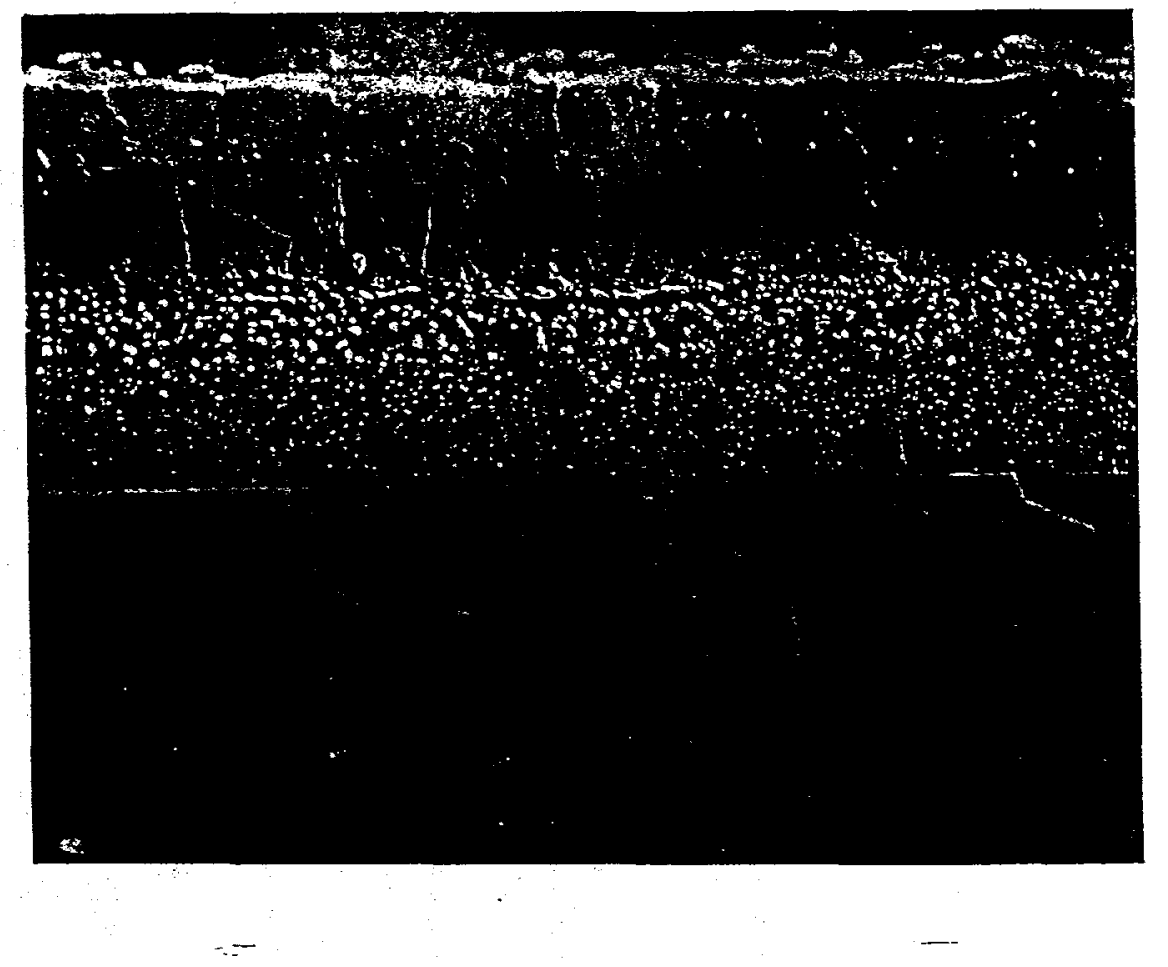

Photo 2: The aluminide produced by diffusing SermeTel 963 into $316 \mathrm{~L}$ stainless steel for 4 hours at $980 \mathrm{C}(1800 \mathrm{~F})$.

(mount A2089, unetched differential interference contrast, 375x) 


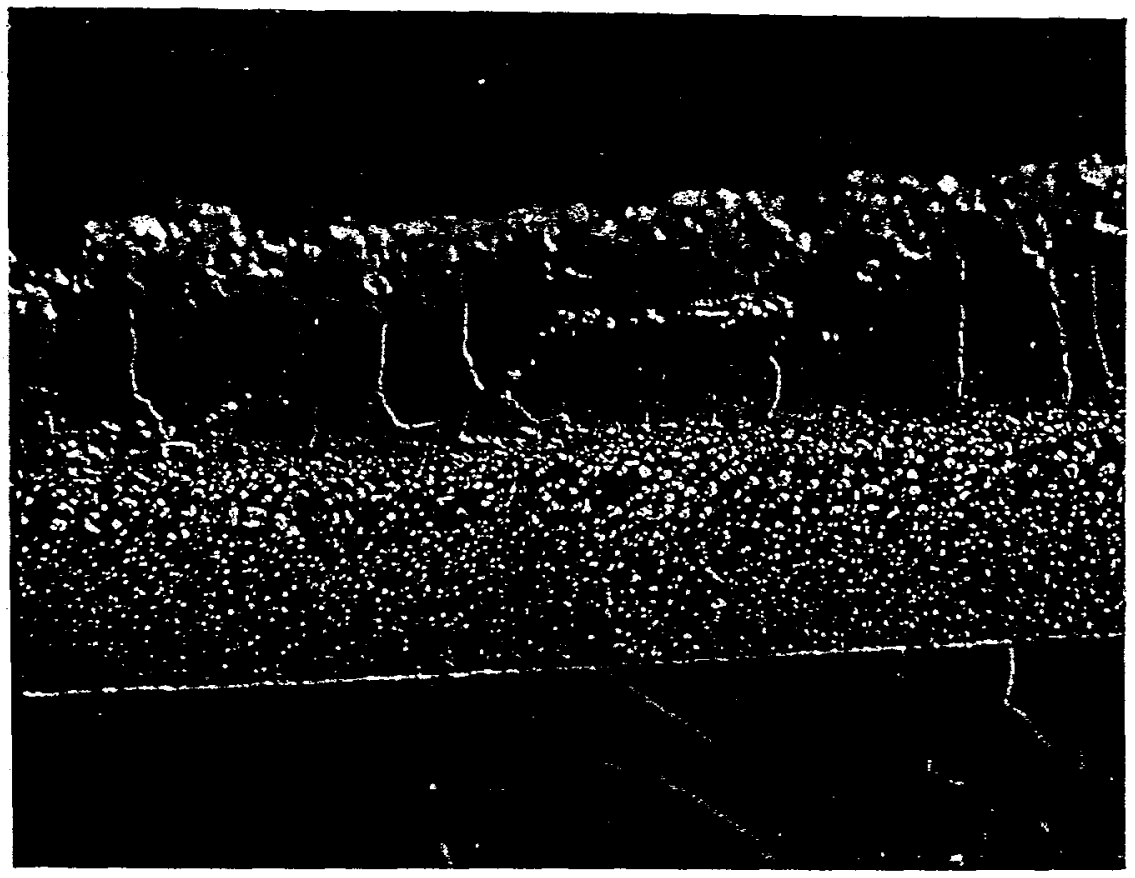

Photo 3: $\quad$ Aluminide produced by diffusing SermAlcote 1619 vapor phase slurry aluminide on $316 \mathrm{~L}$ stainless steel at $980 \mathrm{C}(1800 \mathrm{~F})$ for 4 hours.

(unetched differential interference contrast, $375 x$ ) 


\section{TABLE ESLURRY ALUMINIDES ON 316L SS}

\begin{tabular}{|c|c|c|c|}
\hline COATING & & THICKNESS & AI CONTENT \\
\hline SermeTel 962 & $\begin{array}{l}\text { Outer layer } \\
\text { Middle layer } \\
\text { Inner layer }\end{array}$ & $\begin{array}{l}1.3 \mathrm{mils} \\
\frac{3.5 \mathrm{mils}}{4.8 \mathrm{mils}}\end{array}$ & $\begin{array}{l}7.12 w t \% \\
10.28 \\
6.30\end{array}$ \\
\hline SermeTel 963 & $\begin{array}{l}\text { Outer layer } \\
\text { Middle layer } \\
\text { Inner layer }\end{array}$ & $\begin{array}{l}2.1 \text { mils } \\
\frac{2.2 \text { mils }}{4.3 \text { mils }}\end{array}$ & $\begin{array}{l}36.01 \text { wt \% } \\
30.95 \\
8.28\end{array}$ \\
\hline SermAlcote 1619 & $\begin{array}{l}\text { Outer layer } \\
\text { Middle layer } \\
\text { Inner layer }\end{array}$ & $\begin{array}{l}2.6 \text { mils } \\
\frac{2.6 \text { mils }}{5.2 \text { mils }}\end{array}$ & $\begin{array}{l}25.45 w t \% \\
23.23 \\
7.26\end{array}$ \\
\hline
\end{tabular}




\section{Quali-Tech, Inc.}

MATERIALS ANALYSIS LABORATORY

REPORT NUMBER:

PREPARED FOR:

P.O. NUMBER:

SUBJECT :

ANALYTICAL

TECHNIQUES :
$99-11864$

Mr. Bruce McMordie SERMATECH INTERNATIONAL, INC.

155 South Limerick Road

Limerick, PA 19468-1699

L103098 M

Three Mounts - A2088, A2089 and A2090

Ref.: B092598A

Scanning Electron Microscopy (SEM)

Energy Dispersive $X$-Ray Spectroscopy (EDS)

PURPOSE OF ANALYSIS

Determine coating composition.

\section{RESULTS}

The coating composition was determined in three areas $(M-1,2)$ :

1. Thin sporadic outer layer;

2. Middle;

3. Inner.

The results are presented in Table I attached.

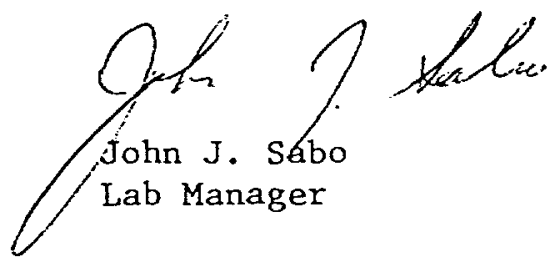

JJS $\mathbf{j}$ tb

Enclosures: Table I

Two Micrographs (M-1 and $M-2)$

Returned Sample 


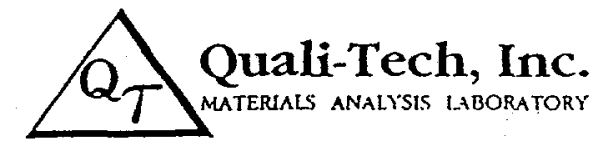

99-11864

TABIE I

ELEMENTAL COMPOSITION

(WEIGHT \%)

\section{SAMPLE}

$$
\begin{aligned}
\text { A/2088 - } & \text { Outer } \\
& \text { Middle } \\
& \text { Inner }
\end{aligned}
$$

$\begin{aligned} & \text { A/2089 - } \text { Outer } \\ & \text { Middle } \\ & \text { Inner }\end{aligned}$

A/2090 - Outer Middle Inner

-

*Average of two readings.

\begin{tabular}{rrrrrrrr}
\multicolumn{1}{c}{ A1 } & Si & Cr & Fe & Ni & Mo & P \\
\cline { 6 - 7 } 7.12 & 0.48 & 14.48 & REM & 4.18 & 1.63 & 2.83 \\
10.28 & 0.22 & 11.75 & REM & 11.25 & 0.74 & - \\
6.30 & 0.56 & 16.63 & REM & 9.57 & 1.54 & - \\
36.01 & - & 17.69 & REM & 3.28 & 1.04 & - \\
30.95 & - & 11.15 & REM & 9.83 & 0.56 & - \\
8.28 & 0.47 & 18.82 & REM & 8.83 & 1.66 & - \\
25.45 & 0.49 & 11.33 & REM & 6.64 & 0.65 & 1.63 \\
23.23 & 0.17 & 10.67 & REM & 8.71 & 1.01 & - \\
7.26 & 0.42 & 17.52 & REM & 9.91 & 1.97 & -
\end{tabular}




\section{$\mathrm{Q}_{T}$ Quali-Tech, Inc.}

\section{9-11864}

M-1

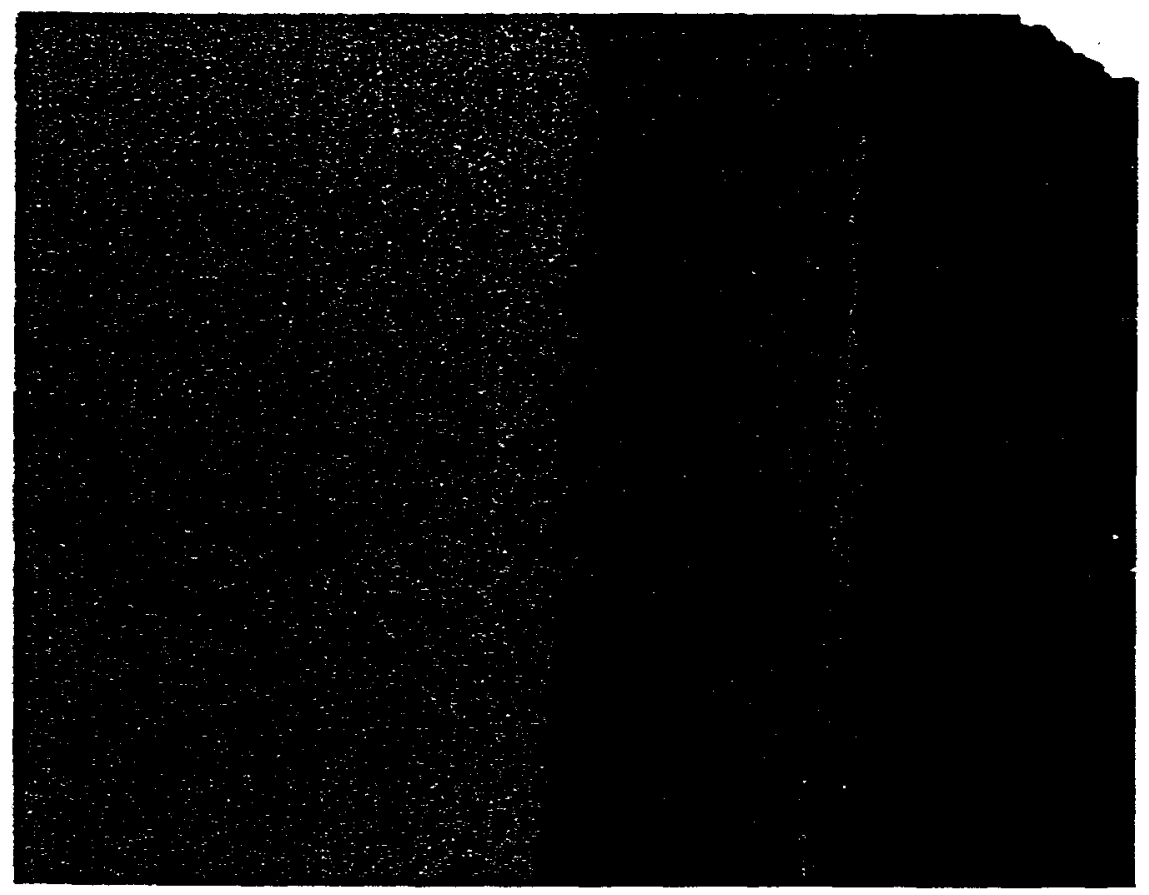

M-2

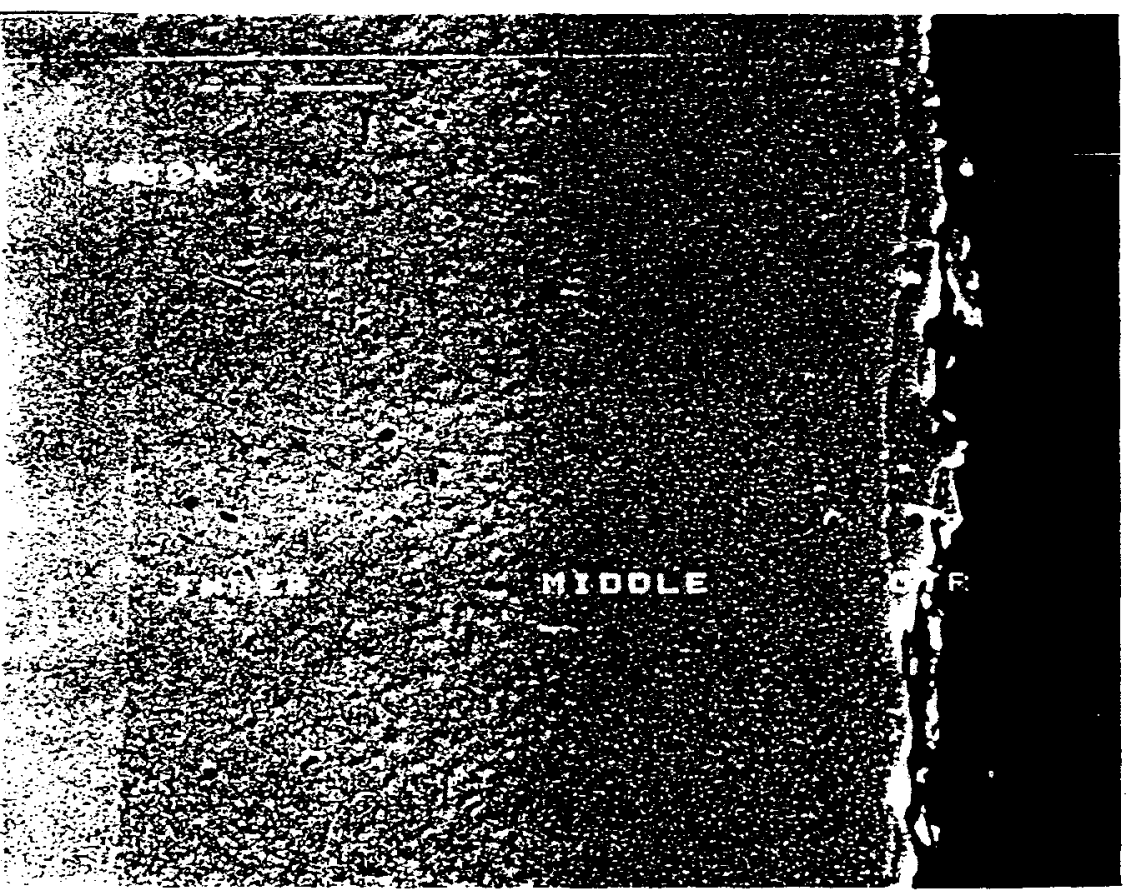


WSRC-TR-98-00429

Appendix B

STATEMENT OF WORK

FOR SERMATECH 


\section{Statement of Work for \\ Coating $\mathrm{Cu}$ Foam Filled Heat Exchanger with Aluminide \\ REVISION 0 \\ Sept. 8, 1998}

1. SCOPE:

Subcontractor to perform aluminide coating of heat exchanger sub-elements for Westinghouse Savannah River Company. All work shall be performed at the subcontractor facility or their designate.

2. REFERENCE:

NA

3. WORK REQUIREMENT:

3.1 Technical Requirements:

3.1.1 Subcontractor to provide aluminide coatings of heat exchanger sub-elements (material type 316L stainless steel) for six (6) samples per sub-contractors best estimate of green thickness and diffusion conditions: Diffusion temperature shall not exceed $980^{\circ} \mathrm{C}\left(1800^{\circ} \mathrm{F}\right)$. Two coating slurries shall be tried, one that uses a liquid phase formation and the other that uses a vapor phase. A maximum of four diffusion trials will be used. Multiple diffusion heat treatments may be used on the same sample to modify the coating attributes. Work shall result in written documentation of the method of manufacture. The documents shall be made available at the subcontractors site for review by WSRC personnel.

\subsection{2 - Final coating technical requirements:}

3.1.2.1 The diffused thickness of the aluminide coating shall be on average $0.001-$ 0.004 inch. Individual measurements as low as 0.0005 inch and as high as

, 0.005 are permitted, no more than two extremes per cross-section. Coating shall transition smoothly from one thickness to another.

3.1.2.2 The aluminum content of the outer $25 \%$ of the coating shall be between 18 and $35 \% \mathrm{Al}$. Semi-quantitative X-ray energy dispersion analysis, microprobe, or $\mathrm{x}$ ray fluorescence are acceptable to determine the $\mathrm{Al}$ content.

3.1.2.3 The coating shall be uniform in thickness with thickness transitions occurring in a continuous rather than abrupt manner, and free from defects such as cracks, chips and delamination. 
3.1.2.4 The coating shall exhibit a dual layer microstructure with an aluminum rich iron aluminide outer layer and an inner diffusion layer.

3.2 WSRC Furnished Materials:

WSRC shall provide six (6) $4-5$ inch long 2 inch diameter heat exchanger pieces for coating with aluminum or aluminum alloy slurries and diffusing to form an aluminide coating. At least two (2) shall be filled with $\mathrm{Cu}$ foam and welded shut on the ends, surrogate type 316L stainless steel samples may be used for the initial trials to speed the processing.

3.3 Site Conditions:

NA

3.4 Period of Performance/Schedule Requirements:

Period of performance shall begin upon award of contract and extend for a period not to exceed eight (8) weeks.

3.5 Deliverables

Subcontractor shall return samples, aluminum content data, and micrographs from all trials and samples after completion of contract.

4.0 ACCEPTANCE OF SERVICE:

The service shall be complete when the samples and data are returned/supplied to WSRC.

5.0 - ATTACHMENTS:

NA -

Cost estimates: $\quad \$ 500 /$ heat treat $--\$ 100 /$ sample analysis

extended cost $\$ 2000$ 
WSRC-TR-98-00429

Appendix C

SERMATECH MICROHARDNESS

TEST REPORT 


\section{SLURRY ALUMINIZING OF 316L STAINLESS STEEL}

Background:

See Project Report B092598A

Test Procedure:

At the request of Westinghouse/Savannah River, three diamond pyramid hardness indentations were made in the "middle" zone of the aluminides formed on $316 \mathrm{~L}$ by the SermeTel 963 and SermAlcote 16.19 slurries. A 100 gram load was used.

Results and Discussion:

No cracks formed around the indentations in either aluminide (Photo S1). The aluminide formed from 963 was harder than that formed from 1619 (670 DPH compared to 465 DPH).

Fine cracks were evident in the middle zone of both aluminides. The cracks were more pronounced in the aluminide formed from SermAlcote 1619 (Photo S2). In both cases, the cracks ended at the interface with the innermost diffusion zone.

\section{Conclusions:}

- At a 100 gram load, a pyramid hardness indenter does not produce cracks in an aluminide produced from SermeTel 963 or SermAlcote 1619.

The incidence of cracks is -greater in an aluminide formed from SermAlcote 1619 on $316 \mathrm{~L}$ stainless steel, than it is in an aluminide formed from SermeTel 963.
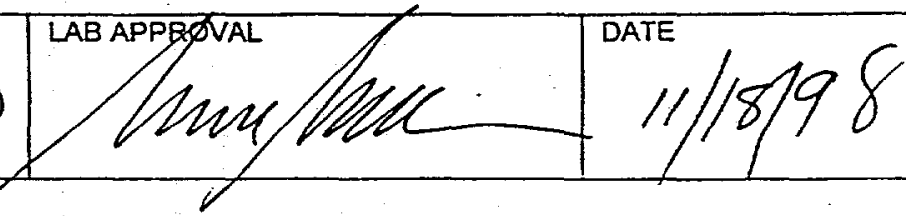

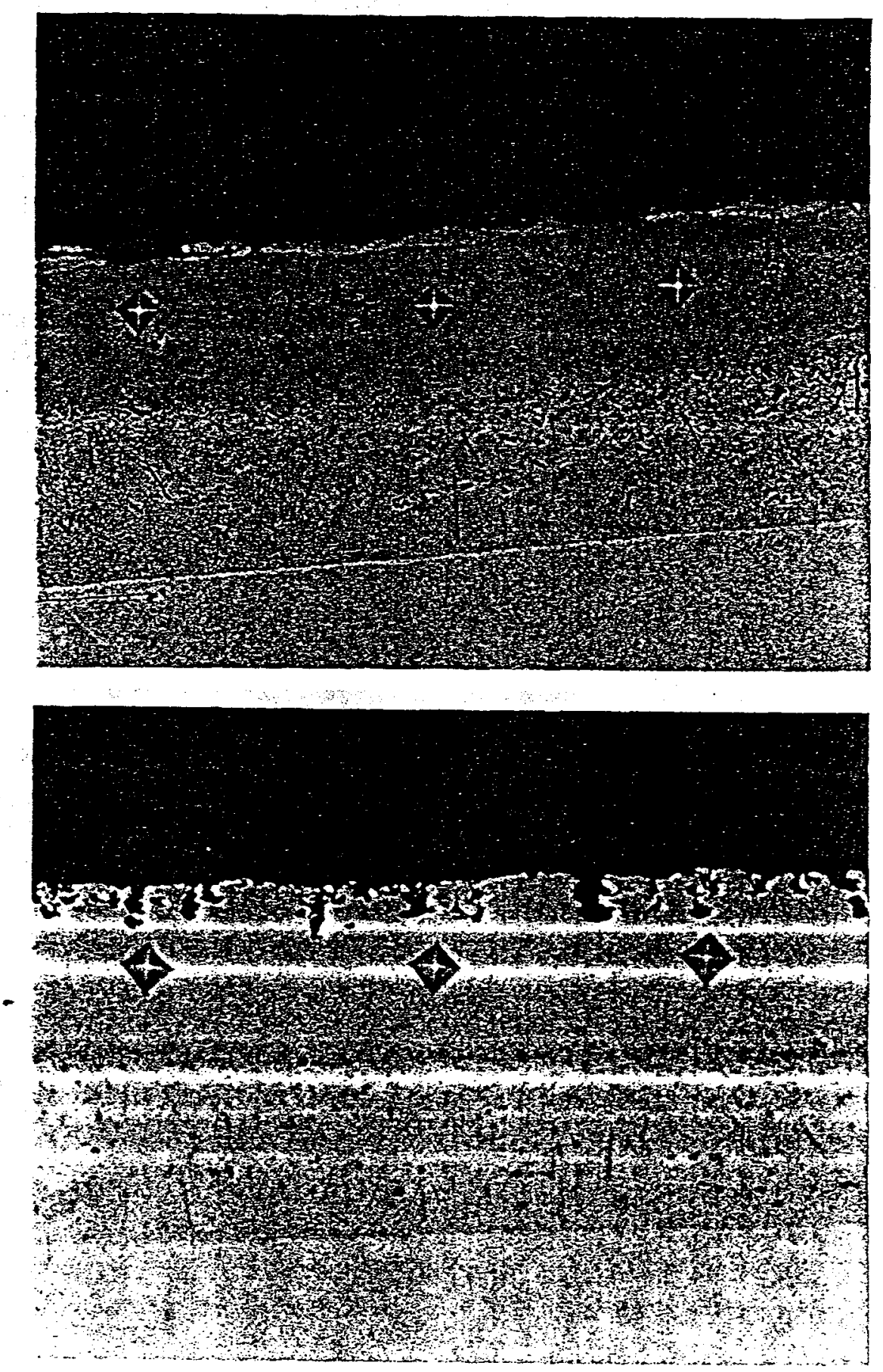

Photo S1: Diamond pyramid indentations in aluminides formed from SermeTel 963 (top) and SermAlcote 1619 (bottom) on 316L stainless steel.

Unetched, $375 x$ 

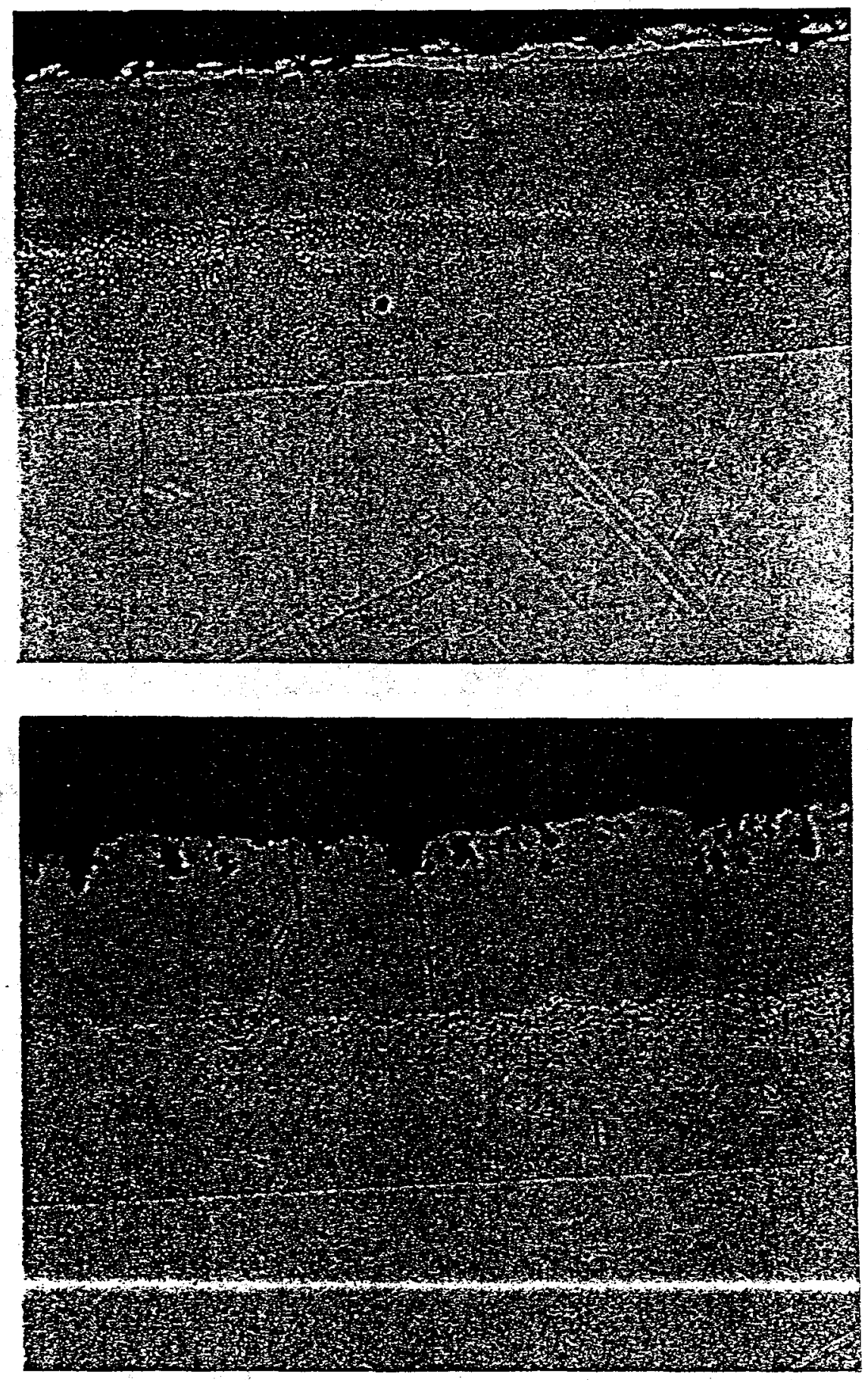

Photo S2: Cracks in SermeTel 963 aluminide (top) and SermAlcote 1619 aluminide on $316 \mathrm{~L}$ stainless steel.

Unetched, $375 x$ 
WSRC-TR-98-00429

\section{Appendix D}

NON-DESTRUCTIVE LIQUID

PENETRANT EXAMINATION 
NONDESTRUCTIVE EXAMINATION REPORT LIQUID PENETRANT EXAMINATION

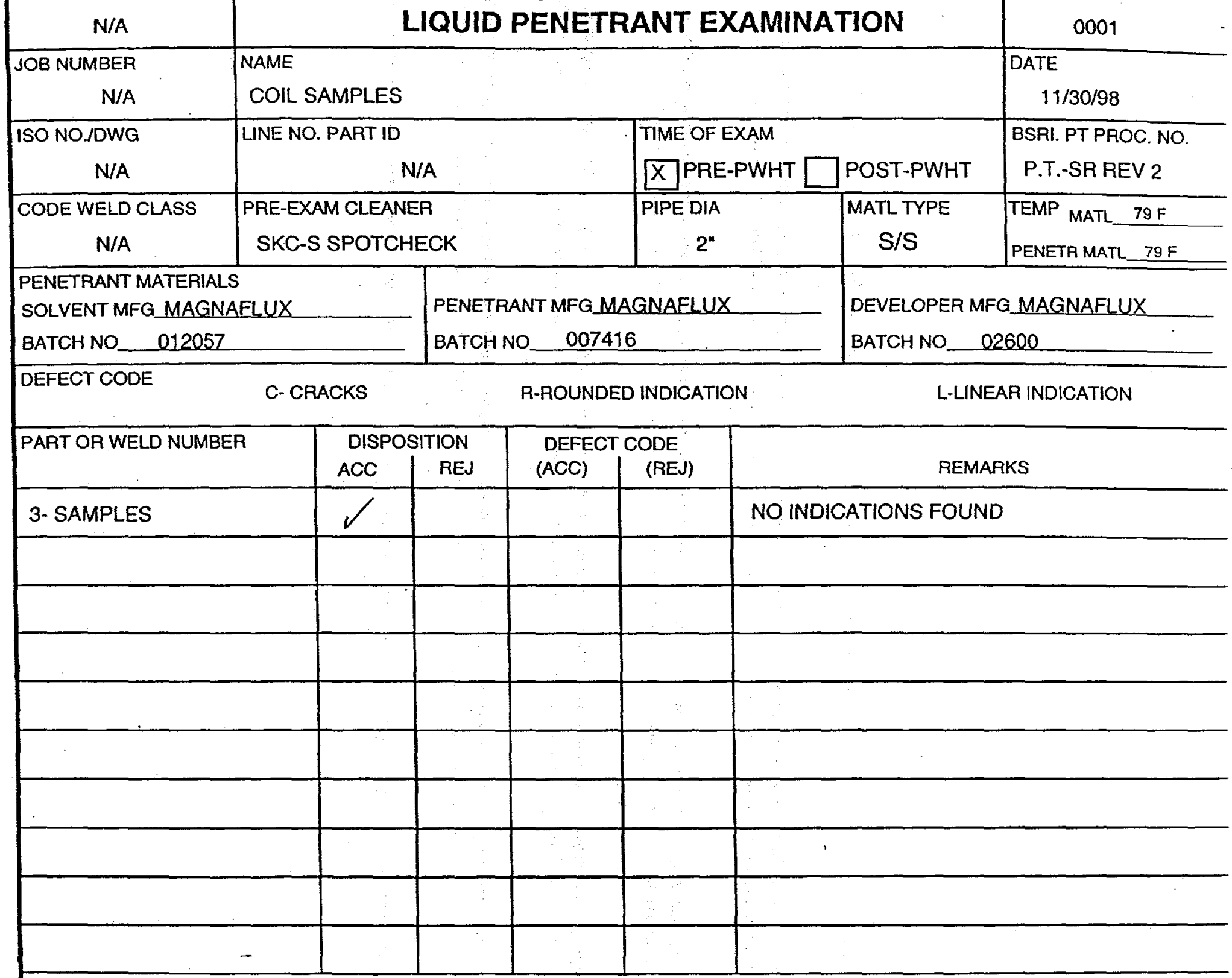

SKETCH

NOTES

DWELL TIME 50 MINUTES

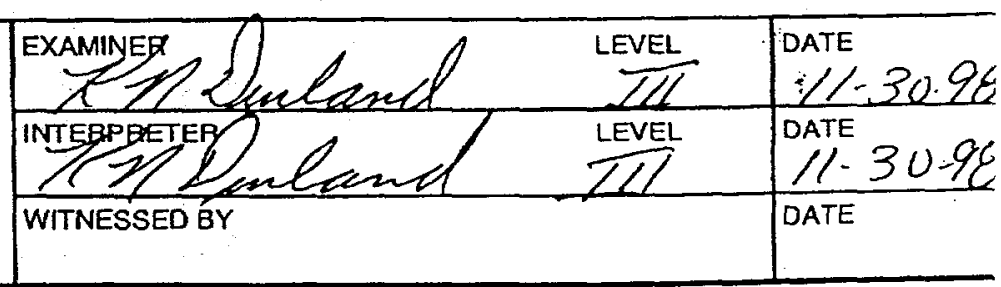

